\title{
Effect of iron-folic acid supplementation on change of hemoglobin among visceral Leishmaniasis patients in northwest Ethiopia: a retrospective follow up study
}

Tadele Mulaw ${ }^{1}$, Amare Tariku², Adino Tesfahun Tsegaye ${ }^{3}$ and Zegeye Abebe ${ }^{2^{*}}$ (D)

\begin{abstract}
Background: An individual with visceral Leishmaniasis $(\mathrm{VL})$ commonly present with anemia and one of the $\mathrm{VL}$ treatment center in northwest Ethiopia has been recommended iron-folic acid supplementation to these patients. But there is no documented evidence whether iron-folic acid supplementation improves the hematological profile of patients. Therefore, the study aimed to assess change in hemoglobin $(\mathrm{Hb})$ and its determinant factors among $\mathrm{VL}$ patients with and without iron-folic acid supplementation in northwest Ethiopia.

Methods: A retrospective cohort study was conducted from January 2015 to December 2016. Data were entered into Epi-Data version 3.1 and transferred to Statistical Package for Social Science (SPSS) version 20 for analysis. Independent sample T-test and linear regression were used to compare the change in $\mathrm{Hb}$ and identify factors associated with a change in $\mathrm{Hb}$, respectively. A 95\% confidence level and p-values less than 0.05 were used determine statistically significant.

Results: From a total of 602 VL patients, 299 (49.7\%) were from University of Gondar hospital. The mean ( \pm SD) change of $\mathrm{Hb}$ from baseline to end of treatment was $0.99( \pm 1.64)$ and $1.61( \pm 1.88) \mathrm{g} / \mathrm{dl}$ with and without iron-folate supplementation, respectively, with mean difference $0.62,95 \% \mathrm{Cl}(0.34,0.90)$ and a $p$-value of $<0.0001$. In multiple linear regressions, combination therapy of sodium stibogluconate-paramomycin (SSG-PM) was positively associated with a change of $\mathrm{Hb}(\beta[S E, p]$ : $0.710 / 0.15,<0.0001)$. Whereas age $(-0.030 / 0.009,0.001)$, nasal bleeding $(-0.261 / 0.123,0.035)$, baseline white blood cell $(-0.139 / 0.044,0.002)$ and hemoglobin $(-0.513 / 0.031,<0.0001)$, end of treatment spleen size $(-0.059 / 0.015,<0.0001)$ and iron-folic acid supplementation $(-0.574 / 0.163,<0.0001)$ were negatively associated with change of $\mathrm{Hb}$.

Conclusion: Iron-folic acid supplementation had a negative effect on the change of $\mathrm{Hb}$. A combination therapy of SSG-PM, age, nasal bleeding, baseline white blood cells and $\mathrm{Hb}$, and iron-folic acid supplementation were the determinants of change of $\mathrm{Hb}$. Therefore, avoiding iron-folic acid supplementation and strengthening VL treatment with a combination of SSG-PM and, and early identification of complications is recommended for a better outcome.
\end{abstract}

Keywords: Anemia, Visceral Leishmaniasis, Iron-folic acid supplementation and change of hemoglobin

\footnotetext{
* Correspondence: zegeye24@gmail.com

${ }^{2}$ Department of Human Nutrition, Institute of Public Health, College of

Medicine and Health Sciences, University of Gondar, Gondar, Ethiopia

Full list of author information is available at the end of the article
}

(c) The Author(s). 2018 Open Access This article is distributed under the terms of the Creative Commons Attribution 4.0 International License (http://creativecommons.org/licenses/by/4.0/), which permits unrestricted use, distribution, and reproduction in any medium, provided you give appropriate credit to the original author(s) and the source, provide a link to the Creative Commons license, and indicate if changes were made. The Creative Commons Public Domain Dedication waiver (http://creativecommons.org/publicdomain/zero/1.0/) applies to the data made available in this article, unless otherwise stated. 


\section{Background}

Anemia is a condition characterized by a decrease in hemoglobin concentration below the acceptable range [1]. It is a major global public health problem, especially in developing countries. According to the World Health Organization (WHO) estimate, it affects near two billion, one-quarter of the global population. Among this, Iron deficiency anemia (IDA) is responsible for approximately $50 \%$ of all types of anemia and 800, 000 deaths per year worldwide [2]. The consequences of anemia are numerous, including negatively affect cognitive performance and motor development leading to fatigue, low productivity, reduced work capacity and cognitive function, retarded physical growth, and impaired school performance [3].

In addition to nutritional deficiency, anemia is caused by infectious diseases. For instance, it is caused by one of a vector born and neglected protozoal infection, Leishmaniasis. The pathology of the disease depends on the Leishmania species, and visceral leishmaniasis (VL), caused by Leishmania donovani andLeishmania infantum, is the most severe and fatal with 40,000 s death annually $[4,5]$. The disease is affecting largely the poorest of the poor, and highly associated poor health care systems [6].

Globally, more than $90 \%$ of VL cases occurred in six countries, including Brazil, Ethiopia, India, Bangladesh, South Sudan and Sudan [7]. Sub-Saharan Africa remains the region with the second highest incidence of $\mathrm{VL}$ in the world, $15 \%$ of the global burden, next to India [8]. The country Ethiopia bears the second higher incidence in East Africa, with 2000-4500 new cases per year. Individuals with VL present with anemia, hepatosplenomegaly, fever, nasal bleeding, discoloration of the skin of the hands, feet, abdomen, and face, which gave the name "kala-azar," or "black disease" to the condition. But anemia, normocytic normochromic anemia, is a typical symptom during VL primarily caused by three mechanisms; blood loss, RBC destruction, and hemolysis, although micronutrient deficiency, particularly iron, folic acid, and vitamin B12 plays a major role in developing anemia [9-11]. In addition, duration of illness, concomitant diseases, intestinal helminths and nutritional status play a further contributory role for anemia [12].

Though countries as whole have been accelerating in reducing the incidence of $\mathrm{VL}$, including developing the national guideline, early diagnosis and treatment, reservoir and vector control, and vaccination, however, functioning control programmes are not sufficient and disparities exist in the incidence of VL across countries.

Hematological improvement is expected within 2 weeks and complete recovery within 4 to 6 weeks after initiation of VL treatment weeks [13]. In northwest Ethiopia, the Abdurafi Medicine Sans Frontiers Holland Kala-azar treatment center (MSF-KTC) has been recommended iron and folic acid supplementation for those patients with VL. But the other treatment center, University of Gondar Leishmaniasis Research and Treatment Center (UoG-LRTC), didn't supplement iron-folic acid. In addition, there is also inconclusive evidence regarding the effect of iron and folic acid supplementation on change of hemoglobin $[14,15]$. Therefore, the study aimed to answer the question whether iron and folic acid have a better improvement for anemia among VL patients or not.

\section{Methods}

\section{Study design and setting}

An institution based retrospective cohort study was conducted from March to April 2017 at the University of Gondar Leishmaniasis Research and Treatment Center (UoG-LRTC) and Abdurafi Medicines sans Frontiers Holland kala-azar treatment center (MSF-KTC), northwest Ethiopia. This part of the country is main endemic foci for visceral leishmaniasis, including, Addis zemen, Metema, Quara, West Armachiho, Humera, and Ethio- Sudan border [16].

Both treatment centers are the larger as well as specialized leishmaniasis diagnosis and treatment centers in this region. In addition, both are supported by the non-governmental organization's Drugs for Neglected Diseases initiative (DNDi) and Médecins sans Frontières (MSF), respectively. Each center has its own admission ward, pharmacy, and laboratory room, where routine hematological and clinical chemistry tests are done.

Admitted patients with VL in both treatment centers are routinely evaluated and the findings are documented in their respective chart. The patient's hematology, blood chemistry, and other investigations are determined as part of other clinical evaluation modalities. Nutritional assessment, such as weight, and Body mass index are measured at admission, weekly and at discharge. In addition to VL treatment, Abdurafi MSF-KTC has been giving Iron and folic acid supplementation (IFS) to VL patients. But UoG-LRTC has not recommended iron and folic acid (NIFS) supplementation. MSF-KTC has a well-established database system for archiving patient information, whereas UoG-LRTC has a chart archiving room to keep it safe. Hence, we retrieved the data from both treatment centers easily.

\section{Sample size and sampling procedure}

All adults (age $\geq 18$ years) VL patients completed anti-leishmaniasis treatment from 2015 to 2016 were included in the study. But patients co-infected with HIV, 
received a blood transfusion, pregnant women, prolonged hospitalization ( $>20$ days) and discharged before 15 days of VL treatment were excluded. The size of the study was determined using the following assumption; $95 \%$ level of confidence, $80 \%$ power, a ratio of $1: 1$ and the mean $( \pm \mathrm{SD})$ hemoglobin of non-exposed and an exposed group were 10.5 and 9.9, \pm 2.6 , respectively. Finally, by considering $10 \%$ incompleteness a size of 196 was obtained from each group. But we included all VL patients who fulfilled the inclusion criteria to increase the power.

\section{Data collection tool and procedure}

A structured data extraction tool was adopted from the national VL treatment guideline and the data were extracted by four data collectors. All data collectors have a rich experience in data management and handling and they are also trained in Good Clinical Practice (GCP). In addition, one-day training was given to data collectors with practical demonstration. During the data collection period, a close supervision was done by the principal investigator. Appropriate feedback was given before the next data collection period.

\section{Operational definitions \\ Change of hemoglobin}

Means either increase or decrease a unit of $\mathrm{g} / \mathrm{dl}$ from the baseline patient's hemoglobin [17].

\section{Anemia}

It was classified using the level of hemoglobin in $\mathrm{g} / \mathrm{dl}$. Hemoglobin status between $12-16 \mathrm{~g} / \mathrm{dl}$ and $13-17 \mathrm{~g} / \mathrm{dl}$ were considered as normal for female and male patients, respectively. Mild anemia for females and male patients ranged between 11 and $11.9 \mathrm{~g} / \mathrm{dl}$ and $11-12.9 \mathrm{~g} / \mathrm{dl}$ of hemoglobin, respectively. For both sexes, a hemoglobin level of $8-10.9 \mathrm{~g} / \mathrm{dl}$ and $<8 \mathrm{~g} / \mathrm{dl}$ were considered as moderately and severely anemic, respectively [18].

\section{Body mass index (BMI)}

means weight divided by height in meter square $\left(\mathrm{kg} / \mathrm{m}^{2}\right)$ and classified as 18.5 to 24.5 normal; 17 to 18.49 mild; 16 to 17 moderate and less than $16 \mathrm{~kg} / \mathrm{m}^{2}$ severe chronic energy deficiency [19].

\section{Splenomegaly}

It is defined as palpable spleen below the costal margin along the line of growth [20].

\section{Data processing and analysis}

The data were entered into EpiData software version 3.1 and transformed to SPSS version 20 for data management and analysis. Percentages, means and standard deviations were used to present descriptive results.
Baseline results were analyzed using the chi-square test for categorical variables. Independent sample T-test was used to compare the change in hemoglobin from baseline to end of VL treatment with and without iron-folic acid supplementation. The assumption of normality was checked both graphically and using Shapiro-wilk test. We used linear regression to identify possible predictors of change of hemoglobin. Variables with a $p$-value $<0.2$ in simple linear regression was entered into multiple linear regression using backward methods. Finally, a 95\% $\mathrm{CI}$ and a p-value of less than 0.05 were used to determine statistically significant.

\section{Results}

Study population and baseline clinical characteristics

A total of 602 VL patients' charts were reviewed. Almost equal number of cases from each treatment centers, 299 (49.7\%) from UOG-LRTC and 303 (50.3\%) from Abdurafi MSF-KTC. The majority, 99.5\%, and nearly half, 299 (49.7\%), were males and migrant workers, respectively. In both treatment centers, young males (18-27 years) were the most affected group, $78.5 \%$ from supplemented and $72.9 \%$ from the non-supplemented group.

Regarding clinical symptoms at the time of diagnosis, overall, 296 (97.7\%) reported fever, 269 (88.8\%) loss of appetite, and 244 (80.5\%) weight loss. Concerning their nutritional status, 72.9 and $88.6 \%$ were malnourished on admission among supplemented and non-supplemented groups, respectively (Table 1 ).

\section{Diagnosis mechanism and treatment modality of patients in both treatment sites}

In case of the diagnosis criteria, more than $90 \%$ in Abdurafi MSF-KTC were diagnosed by serological test and case definition. Whereas, 269 (90\%) in UoG-LRTC were confirmed by parasitological examination. The majority of patients, 215 (71\%) and 269 (90\%) in MSF-KTC and UoG-LRTC were treated with a combination of sodium stibogluconate and paramomycin (SSG-PM) injection for 17 days. At the end of treatment, 294 (97\%) in IFS and 295 (98.7\%) in NIFS groups were declared initial cure (Table 2).

\section{Hematological profile of patients at baseline and end of treatment}

The overall prevalence of anemia was 303 (100\%) and $300(99 \%)$ at the baseline and end of treatment among the supplemented group, respectively. Regarding the severity of anemia, 147 (48.5\%) and 90 (29.7\%) of the patients had severe anemia at baseline and end of treatment. Similarly, the overall prevalence of anemia among the non-supplemented group was 291 (97.4\%) and 278 (93\%) at beginning and end of treatment, respectively. 
Table 1 Socio-demographic and baseline clinical characteristics of VL patients at UoG-LRTC and MSF-KTC northwest Ethiopia, 2017

\begin{tabular}{|c|c|c|c|}
\hline \multirow[t]{3}{*}{ Variables } & \multicolumn{2}{|c|}{ Treatment facilities } & \multirow[t]{3}{*}{$P$-value } \\
\hline & $\begin{array}{l}\text { MSF-KTC } \\
(n=303)\end{array}$ & $\begin{array}{l}\text { UoG-LRTC } \\
(n=299)\end{array}$ & \\
\hline & $n(\%)$ & $n(\%)$ & \\
\hline
\end{tabular}

\begin{tabular}{llll}
\hline Sex & & & \\
Male & $301(99.3)$ & $298(99.7)$ & 0.56 \\
Female & $2(0.7)$ & $1(0.3)$ &
\end{tabular}

Age in years

$\begin{array}{lll}18-27 & 238(78.5) & 218(72.9) \\ 28-37 & 47(15.5) & 64(21.4) \\ 38-47 & 12(4) & 16(5.4) \\ 48-57 & 6(2) & 1(0.3)\end{array}$

Residence

Stable residents
Migrant workers
Duration of illness
$\leq 6$ weeks
$>6$ weeks

Fever $>2$ Weeks

$$
\text { Yes }
$$

No

Abdominal swelling

Yes

No

Easy fatigability

Yes

No

Repeated attack of malaria

Yes

Weight loss

Yes

No

Loss of appetite

Yes

No

Nasal bleeding

Yes

No

Diarrhea

Yes
No
Cough
Yes
No

No

$\begin{array}{ll}254(83.8) & 49(16.4) \\ 49(16.2) & 250(83.6) \\ 230(75.9) & 192(64.2) \\ 73(24.1) & 107(35.8 \\ 296(97.7) & 287(96) \\ 7(2.3) & 12(4)\end{array}$

$196(64.7) \quad 116(38.8)$

$107(35.3) \quad 183(61.2)$

$194(64) \quad 179(59.9)$

$109(36) \quad 120(40.1)$

$35(11.6) \quad 119(39.8)$

$268(88.4) \quad 180(60.2)$

$244(80.5) \quad 274(91.6)$

$59(19.5) \quad 25(8.4)$

$269(88.8) \quad 270(90.3)$

$34(11.2) \quad 29(9.7)$

$167(55.1) \quad 68(22.7)$

$136(44.9) \quad 231(77.3)$

$41(13.5) \quad 36(12)$

$262(86.5) \quad 263(88)$

$157(51.8) \quad 143(47.8)$

$146(48.2) \quad 156(52.2)$
0.001

0.52
Table 1 Socio-demographic and baseline clinical characteristics of VL patients at UoG-LRTC and MSF-KTC northwest Ethiopia, 2017 (Continued)

\begin{tabular}{|c|c|c|c|}
\hline \multirow[t]{3}{*}{ Variables } & \multicolumn{2}{|c|}{ Treatment facilities } & \multirow[t]{3}{*}{$P$-value } \\
\hline & $\begin{array}{l}\text { MSF-KTC } \\
(n=303)\end{array}$ & $\begin{array}{l}\text { UoG-LRTC } \\
(n=299)\end{array}$ & \\
\hline & $n(\%)$ & $n(\%)$ & \\
\hline \multicolumn{4}{|l|}{ Pale conjunctiva } \\
\hline Yes & $230(75.9)$ & $198(66.2)$ & \multirow[t]{2}{*}{0.01} \\
\hline No & $73(24.1)$ & $101(33.8)$ & \\
\hline \multicolumn{4}{|l|}{ Splenomegally } \\
\hline Yes & $292(96.4)$ & $286(95.7)$ & \multirow[t]{2}{*}{0.66} \\
\hline No & $11(3.6)$ & $13(4.3)$ & \\
\hline \multicolumn{4}{|l|}{ Hepatomegally } \\
\hline Yes & $61(20.1)$ & $72(24.1)$ & \multirow[t]{2}{*}{0.26} \\
\hline No & $242(79.9)$ & $227(75.9)$ & \\
\hline \multicolumn{4}{|l|}{ Lyphadnopathy } \\
\hline Yes & $11(3.6)$ & $7(2.3)$ & \multirow[t]{2}{*}{0.34} \\
\hline No & $292(96.4)$ & $292(97.7)$ & \\
\hline \multicolumn{4}{|l|}{ Jaundice } \\
\hline Yes & $20(6.6)$ & $26(8.7)$ & \multirow[t]{2}{*}{0.34} \\
\hline No & $283(93.4)$ & $273(91.3)$ & \\
\hline \multicolumn{4}{|l|}{ Bilateral pitting edema } \\
\hline Yes & $38(12.5)$ & $67(22.4)$ & \multirow[t]{2}{*}{0.001} \\
\hline No & $265(87.5)$ & $232(77.6)$ & \\
\hline \multicolumn{4}{|l|}{ Baseline BMI } \\
\hline Normal & $82(27.1)$ & $33(11.4)$ & \multirow[t]{4}{*}{0.001} \\
\hline Mild malnutrition & $96(31.7)$ & $67(22.4)$ & \\
\hline Moderate malnutrition & $73(24.1)$ & $76(25.4)$ & \\
\hline Severe malnutrition & $52(17.1)$ & $122(40.8)$ & \\
\hline
\end{tabular}

Concerning the hematological parameters, the mean $( \pm$ SD) of white blood cells count was $3.4( \pm 1.5) \times 10^{3} / \mu$ l in the supplemented and $3.8( \pm 1.4) \times 10^{3} / \mu \mathrm{l}$ non-supplemented groups at the end of treatment (Table 3 ).

Comparison of change of hemoglobin between two groups The result of a change in hemoglobin $(\mathrm{Hb})$ of VL patients with and without iron-folic acid supplementation is summarized in (Table 4). Among the supplemented group, the mean $( \pm \mathrm{SD}) \mathrm{Hb}$ at baseline and end of treatment was $8( \pm 1.7)$, and $8.99( \pm 1.67) \mathrm{g} / \mathrm{dl}$, respectively. Similarly, the mean $( \pm \mathrm{SD}) \mathrm{Hb}$ at baseline and end of treatment was $8.77( \pm 2.18)$ and $10.38( \pm 1.85) \mathrm{g} / \mathrm{dl}$ among the non-supplemented group, respectively. The finding indicates that there is a statistically significant difference between supplemented and non-supplemented group within the change of $\mathrm{Hb}, P<0.05$. 
Table 2 Diagnosis, management, and concomitant disease or complication of VL from 2015 to 2016 at UoG-LRTC and MSF-KTC northwest Ethiopia, 2017

\begin{tabular}{|c|c|c|}
\hline \multirow[t]{3}{*}{ Variables } & \multicolumn{2}{|c|}{ Treatment facilities } \\
\hline & $\begin{array}{l}\text { MSF-KTC } \\
(n=303)\end{array}$ & $\begin{array}{l}\text { UoG-LRTC } \\
(n=299)\end{array}$ \\
\hline & $n(\%)$ & $n(\%)$ \\
\hline \multicolumn{3}{|l|}{ Diagnosis } \\
\hline Serological and/or clinical & $283(93.4)$ & $30(10)$ \\
\hline Parasitological & $20(6.6)$ & $269(90)$ \\
\hline \multicolumn{3}{|l|}{ Site of aspiration } \\
\hline Spleen & $17(5.6)$ & $220(73.6)$ \\
\hline Bone marrow & $3(1)$ & $49(16.4)$ \\
\hline \multicolumn{3}{|l|}{ Anti leishmaniasis treatment } \\
\hline SSG-PM & $215(71)$ & $269(90)$ \\
\hline Ambisome & $88(29)$ & $30(10)$ \\
\hline \multicolumn{3}{|l|}{ Treatment outcome } \\
\hline Cured & $294(97)$ & $295(98.7)$ \\
\hline Failure & $9(3)$ & $4(1.3)$ \\
\hline \multicolumn{3}{|l|}{ Nutrition support } \\
\hline Yes & $205(67.7)$ & $3(1)$ \\
\hline No & $98(32.3)$ & $296(99)$ \\
\hline \multicolumn{3}{|l|}{ Concomitant diseases/complications } \\
\hline Malaria & $15(5)$ & $31(10.4)$ \\
\hline Pneumonia & $83(27.4)$ & $42(14)$ \\
\hline Ear infection & $13(4.3)$ & $12(4)$ \\
\hline Intestinal parasite & $58(19.1)$ & $64(21.4)$ \\
\hline Skin fungal infection & $3(1)$ & $19(6.4)$ \\
\hline Pancreatitis & $2(0.7)$ & $10(3.3)$ \\
\hline Sever Neutropenia (<500 neutrophils count) & $65(21.5)$ & $43(14.4)$ \\
\hline Others $^{a}$ & $25(8.3)$ & $12(4)$ \\
\hline
\end{tabular}

SSG sodium stibogluconate, PM Paramomycine

ascities Hyperactive spleenomegally, upper respiratory infection, acute kidney

injury, oral candidacies, hemorrhoid, sexually transmitted infection
Factors associated with a change of hemoglobin

According to multivariable linear regression analysis, age, nasal bleeding, iron-folic acid supplementation, end line spleen size, baseline WBC and $\mathrm{Hb}$ count were negatively associated with the change of $\mathrm{Hb}$, whereas a combination of therapy of SSG-PM was positively associated with the change of $\mathrm{Hb}$ (Table 5).

\section{Discussion}

This study was tried to evaluate the effect of iron-folic acid supplementation on change of $\mathrm{Hb}$ among $\mathrm{VL}$ patients. Accordingly, iron-folic acid supplementation had a negative effect on the change of $\mathrm{Hb}$. Iron supplementation may create a conducive environment for parasite survival and growth [15]. In addition, iron has a role in modulating iron superoxide dismutase activity and hydrogen peroxide generation, which are important for parasite differentiation and increasing parasite load. Furthermore, iron availability controls the expression of Leishmania iron transporter1, resulting in iron uptake and an overall increase in intracellular iron availability and parasite load [21].

In this study, the average change of $\mathrm{Hb}$ was increased by $71 \%$ among patients treated with Sodium stibogluconateparomomycin (SSG-PM) combination compared to patients treated with Ambisome alone. This finding is supported by a study finding from Sudan [22]. This explained by the treatment directly killed the parasite inside phagolysosome by inhibiting trypanothione reductase enzyme (an enzyme that recycles oxidized trypanothione to keep the trypanothione in reducing state). So, this decreased the parasite load and may contribute hematological improvement [23].

Age of the patients was one of the predictors of change of $\mathrm{Hb}$. Accordingly, a year increase in age; the average change in $\mathrm{Hb}$ was decreased by $3 \%$. This finding is consistent with the study conducted in East Boston [24]. This could be explained by as the age of patients advanced associated with a gradual decline in the

Table $3 \mathrm{BMI}$ and Hematological profiles of VL patients at baseline and end of treatment with and without iron and folic acid supplementation at UoG-LRTC and MSF-KTC northwest Ethiopia, 2017

\begin{tabular}{|c|c|c|c|c|c|c|}
\hline \multirow[t]{4}{*}{ Characteristics } & \multicolumn{6}{|c|}{ Treatment facilities } \\
\hline & \multicolumn{2}{|c|}{ MSF-KTC $(n=303)$} & \multirow{3}{*}{$P$-value } & \multicolumn{3}{|c|}{ UoG-LRTC $(n=299)$} \\
\hline & Initial & Final & & Initial & Final & $P$-value \\
\hline & Mean $( \pm S D)$ & Mean $( \pm S D)$ & & Mean $( \pm S D)$ & Mean $( \pm S D)$ & \\
\hline WBC $\left(\times 10^{3} / \mu \mathrm{l}\right)$ & $1.98(1.4)$ & $3.4(1.5)$ & $<0.001$ & $2.3(1.3)$ & $3.8(1.4)$ & $<0.001$ \\
\hline Hemoglobin & $8.4(4.7)$ & $9.2(1.7)$ & 0.002 & $9.0(4.8)$ & $10.39(1.8)$ & $<0.001$ \\
\hline Mean cell volume (MCV) & $79.2(7.3)$ & $81.0(9.0)$ & $<0.001$ & $82.0(9.3)$ & $85.5(8.6)$ & $<0.001$ \\
\hline BMI & $17.4(1.6)$ & $17.9(1.8)$ & $<0.001$ & $16.5(1.6)$ & $16.9(1.6)$ & $<0.001$ \\
\hline
\end{tabular}

WBC white blood cell, IQR Interquartile range, SD standard deviation, MCV mean cell Volume, BMI Body Mass Index 
Table 4 Comparison of change of $\mathrm{Hb}$ with and without iron-folic acid supplementation among VL patients at UoG-LRTC and MSF-KTC northwest Ethiopia, 2017

\begin{tabular}{|c|c|c|c|c|c|c|c|c|}
\hline \multirow{3}{*}{$\begin{array}{l}\text { Variable } \\
\text { Iron-folic acid } \\
\text { supplementation }\end{array}$} & \multicolumn{5}{|c|}{ Hemoglobin (g/dl) } & \multicolumn{2}{|c|}{$95 \% \mathrm{Cl}$ of the mean difference } & \multirow[t]{3}{*}{$P$-value } \\
\hline & \multirow[t]{2}{*}{$\mathrm{N}$} & Initial & Final & \multirow{2}{*}{$\begin{array}{l}\text { Change } \\
\text { of mean }( \pm S D)\end{array}$} & \multirow{2}{*}{$\begin{array}{l}\text { Mean } \\
\text { difference }\end{array}$} & \multirow[t]{2}{*}{ Lower } & \multirow[t]{2}{*}{ upper } & \\
\hline & & Mean $( \pm \mathrm{SD})$ & Mean $( \pm \mathrm{SD})$ & & & & & \\
\hline Yes & 303 & $8.0(1.7)$ & $8.99(1.67)$ & $0.99(1.64)$ & & & & $<0.0001$ \\
\hline No & 299 & 8.77 (2.18) & 10.38 (1.85) & $1.61(1.88)$ & 0.62 & 0.34 & 0.90 & \\
\hline
\end{tabular}

immune system, which contribute to the severity of the disease and needs longer time to recover.

The size of spleen at the end of VL treatment was inversely related to the change in $\mathrm{Hb}$ among VL patients. This might be due to sequestration and destruction of red blood cells in enlarged spleen largely contribute to poor recovery from anemia [25]. In addition, blood loss, dysfunction in erythropoiesis, and up-regulated destruction of erythrocytes are the major contributory factors for anemia.

The average change of $\mathrm{Hb}$ was decreased by $26 \%$ among patients with nasal bleeding $(\beta=-0.261 ; 95 \% \mathrm{Cl}$ : $-0.502,-0.019)$. This could be due to very low platelet count as the result of bone marrow suppression. So that the improvement of hemoglobin might not be the same as to those did not have nasal bleeding.

In this study, Iron and folic acid supplementation decreased the average change of hemoglobin by $57 \%$ at $95 \%$ CI $(-0.895,-0.253)$. This finding is consistent with a finding from Belgium which demonstrates adequate supply of iron is needed for the life cycle of Leishmania parasite. In addition, experimental studies on an animal model using iron chelating approach indicates that iron deprivation reduce the rate of promastigotes multiplication in a dose-dependent fashion and iron is also crucial for anti-oxidizing function and other metabolic reaction of the parasite which makes the replication favorable [15].
Similarly, a study conducted in Portugal, the mammalian stage of Leishmania (amastigotes), showed that the amastigotes had high affinity to iron and are also capable of exploiting iron from hemin and hemoglobin for nutritional purposes [14]. In addition, the Leishmania donovani (LD) acquire iron from the host macrophages for survival and growth through different mechanisms. Nevertheless the host macrophages resist by actively sequestering iron from the parasite, the LD directly scavenges iron and utilizes for its intracellular growth [26].

On the other hand, a study conducted in Portugal, the effects of iron supplementation or deprivation on the growth of L.infantum, confirmed iron deficiency did not affect the protozoan growth, whereas iron overload decreased its replication in the liver and spleen of a susceptible mouse strain [27].

\section{Conclusion}

Iron-folic acid supplementation had a negative effect on change in $\mathrm{Hb}$ among $\mathrm{VL}$ patients. A combination therapy of SSG-PM, age, nasal bleeding, baseline white blood cells and $\mathrm{Hb}$, and iron-folic acid supplementation were the determinants of change of $\mathrm{Hb}$. Therefore, avoiding iron-folic acid supplementation and strengthening VL treatment using a combination of SSG-PM during the active infection, and early identification of complications is recommended for a better outcome.

Table 5 Factors associated with a change of Hb among VL patients at UoG-LRTC and MSF-KTC northwest Ethiopia, 2017

\begin{tabular}{|c|c|c|c|c|}
\hline \multirow[t]{2}{*}{ Independent variables } & \multirow{2}{*}{$\begin{array}{l}\text { (B) } \\
\text { Coefficients/ } \\
\text { std-error }\end{array}$} & \multicolumn{2}{|c|}{$95 \%$ (Cl for B) } & \multirow[t]{2}{*}{$P$-value } \\
\hline & & Lower & Upper & \\
\hline Constant & $6.866 / 0.397$ & 6.085 & 7.646 & $<0.0001$ \\
\hline SSG-PM treatment & $0.710 / 0.15$ & 0.416 & 1.005 & $<0.0001$ \\
\hline Age & $-0.030 / 0.009$ & -0.049 & -0.012 & 0.001 \\
\hline Nasal bleeding & $-0.261 / 0.123$ & -0.502 & -0.019 & 0.035 \\
\hline Baseline WBC & $-0.139 / 0.044$ & -0.226 & -0.052 & 0.002 \\
\hline Baseline $\mathrm{Hb}$ & $-0.513 / 0.031$ & -0.574 & -0.452 & $<0.0001$ \\
\hline End of treatment spleen size & $-0.059 / 0.015$ & -0.088 & -0.029 & $<0.0001$ \\
\hline Iron-folic acid supplementation & $-0.574 / 0.163$ & -0.895 & -0.253 & $<0.0001$ \\
\hline
\end{tabular}




\section{Abbreviations}

AOR: Adjusted odds ratio; Cl: Confidence interval; COR: Crude odds ratio; Hb: Hemoglobin; MSF-KTC: Abdurafi Medicine Sans Frontiers Holland Kalaazar treatment center; SD: Standard deviation; SPSS: Statistical Package for Social Science; SSG_PM: Stibogluconate-paramomycin; UoG_LRTC: University of Gondar Leishmaniasis Research and Treatment Center; VL: Leishmaniasis; WHO: World Health Organization

\section{Acknowledgments}

The authors' would like to thank study participants for their willingness to participate in the study and the University of Gondar and Abdurafi MSF-KTC for material support

\section{Funding}

No specific fund was secured for this study.

\section{Availability of data and materials}

Data will be available upon request from the corresponding author.

\section{Authors' contributions}

TMu, ATa and ATSe conceived the study, developed the tool, coordinated data collection, and carried out the statistical analysis and drafted the manuscript. TMu, ATa, ATSe and ZAb participated in the design of the study, developed the tool, participated in the statistical analysis, and drafted the manuscript. All authors read and approved the final manuscript.

\section{Ethics approval and consent to participate}

Ethical approval for this study was obtained from the ethical review board of the University of Gondar. Permission letter was also obtained from the two treatment centers. In addition, personal identifiers were not retrieved and to maintain confidentiality and data were kept locked.

\section{Consent for publication}

Not applicable.

\section{Competing interests}

The authors declare that they have no competing interests.

\section{Publisher's Note}

Springer Nature remains neutral with regard to jurisdictional claims in published maps and institutional affiliations.

\section{Author details}

'University of Gondar Specialized Hospital, Gondar, Ethiopia. ${ }^{2}$ Department of Human Nutrition, Institute of Public Health, College of Medicine and Health Sciences, University of Gondar, Gondar, Ethiopia. ${ }^{3}$ Department of Epidemiology and Biostatistics, Institute of Public Health, College of Medicine and Health Sciences, University of Gondar, Gondar, Ethiopia.

\section{Received: 11 December 2017 Accepted: 10 September 2018}

\section{Published online: 21 September 2018}

\section{References}

1. Alemayehu A, Gedefaw L, Yemane T, Asres Y. Prevalence, severity, and determinant factors of Anemia among pregnant women in south Sudanese refugees, Pugnido, Western Ethiopia. Anemia. 2016:1-11

2. Levi M, Rosselli M, Simonetti M, Brignoli O, Cancian M, Masotti A, et al. Epidemiology of iron deficiency anaemia in four European countries: a population-based study in primary care. Eur J Haematol. 2016:97(6):583-93.

3. Milman N. Anemia - still a major health problem in many parts of the world! Ann Hematol. 2011:90(4):369-77.

4. Wasunna M, Musa A, Hailu A, Khalil EA, Olobo J, Juma R, et al. The Leishmaniasis East Africa platform (LEAP): strengthening clinical tria capacity in resource-limited countries to deliver new treatments for visceral leishmaniasis. Trans R Soc Trop Med Hyg. 2016;110(6):321-3.

5. Ahmed MA, Ahmed AA, Omar SM, Adam GK, Abdallah TM, Ali AA Epidemiology of visceral leishmaniasis among children in Gadarif hospital, eastern Sudan. BMC Public Health. 2016;16(1234):1-4

6. Takele Y, Abebe T, Weldegebreal T, Hailu A, Hailu W, Hurissa Z. Arginase activity in the blood of patients with visceral leishmaniasis and HIV infection. PLoS Negl Trop Dis. 2013;7(1):17.
7. Alvar J, Velez ID, Bern C, Herrero M, Desjeux P, Cano J, et al. Leishmaniasis worldwide and global estimates of its incidence. PLoS One. 2012;7(5):31.

8. Al-Salem W, Herricks JR, Hotez PJ. A review of visceral leishmaniasis during the conflict in South Sudan and the consequences for east African countries. Parasites Vectors. 2016;9(1):460.

9. Goto Y, Cheng J, Omachi S, Morimoto A. Prevalence, severity, and pathogeneses of anemia in visceral leishmaniasis. Parasitol Latinoam. 2017;116(2):457-64

10. Carvalho SCT, Santarém N, Castro H, Costa V, Tomás AM. Heme as a source of iron to Leishmania infantum amastigotes. Acta Trop. 2009;109(2):132-5.

11. Varma N, Naseem S. Hematologic changes in visceral leishmaniasis/kala azar Indian J Hematol Blood Transfus. 2010;26(3):78-82.

12. Allen LH, Rosado JL, Casterline JE, López PME, García OP, Martinez H. Lack of hemoglobin response to iron supplementation in anemic Mexican preschoolers with multiple micronutrient deficiencies. The American journal of clinical nutrition. Am J Clin Nutr. 2000;71(6):1485-94.

13. Ministry of Health. Visceral Leishmaniasis Diagnosis and Treatmnt Guideline for Health Workers in Ethiopia. Guideline for diagnosis, Treatment and prevention of Leishmaniasis in Ethiopia. In: Disease prevention and control department. Addis Ababa: The Federal Democratic Republic of Ethiopia Ministry of Health; 2013

14. Carvalho S, Cruz T, Santarém N, Castro H, Costa V, Tomás AM. Heme as a source of iron to Leishmania infantum amastigotes. Acta Trop. 2009:109(2):131-5.

15. Soteriadou K, Papavassiliou P, Voyiatzaki C, Boelaert J. Effect of iron chelation on the in-vitro growth of Leishmania promastigotes. J Antimicrob Chemother. 1995;35(1):23-9.

16. Gadisa E, Tsegaw T, Abera A, Elnaiem DE, den Boer M, Aseffa A, et al. Ecoepidemiology of visceral leishmaniasis in Ethiopia. Parasit Vectors. 2015;8:381 Epub 2015/07/19.

17. Kawai K, Villamor E, Mugusi FM, Saathoff E, Urassa W, Bosch RJ, et al. Predictors of change in nutritional and hemoglobin status among adults treated for tuberculosis in Tanzania. Int J Tuberc Lung Dis. 2011:15(10):1380-9.

18. Mengesha B, Endris M, Takele Y, Mekonnen K, Tadesse T, Feleke A, et al. Prevalence of malnutrition and associated risk factors among adult visceral leishmaniasis patients in Northwest Ethiopia: a cross sectional study. BMC Res Notes. 2014:7(1):75.

19. Tessfamichael D, Gete A, Wassie M. High prevalence of undernutrition among elderly people in Northwest Ethiopia: a cross sectional study. J Nutrition Health Food Sci. 2014;2(4):1-5.

20. Rotbain EC, Hansen DL, de Muckadell OS, Wibrand F, Lund AM, Frederiksen H. Splenomegaly-diagnostic validity, work-up, and underlying causes. PLoS One. 2017;12(11):e0186674.

21. Mittra B, Cortez M, Haydock A, Ramasamy G, Myler PJ, Andrews NW. Iron uptake controls the generation of Leishmaniainfective forms through regulation of ROS levels. J Exp Med. 2013;210(2):401-16.

22. Saeed AM, Khalil EA, Elhassan AM, Hashim FA, Elhassan AM, Fandrey J, et al. Serum erythropoietin concentration in anaemia of visceral leishmaniasis (kala-azar) before and during antimonial therapy. Br J Haematol. 1998:100(4):720-4

23. Singh OP, Singh B, Chakravarty J, Sundar S. Current challenges in treatment options for visceral leishmaniasis in India: a public health perspective. Infect Dis Poverty. 2016;5(1):19.

24. Salive ME, Cornoni-Huntley J, Guralnik JM, Phillips CL, Wallace RB, Ostfeld AM, et al. Anemia and hemoglobin levels in older persons: relationship with age, gender, and health status. J Am Geriatr Soc. 1992;40(5):489-96.

25. Mueller YK, Kolaczinski JH, Koech T, Lokwang P, Riongoita M, Velilla E, et al. Clinical epidemiology, diagnosis and treatment of visceral leishmaniasis in the Pokot endemic area of Uganda and Kenya. Am J Trop Med Hyg. 2014;90(1):33-9.

26. Das NK, Biswas S, Solanki S, Mukhopadhyay CK. Leishmania donovani depletes labile iron pool to exploit iron uptake capacity of macrophage for its intracellular growth. Cell Microbiol. 2009;11(1):83-94.

27. Vale-Costa S, Gomes-Pereira S, Teixeira CM, Rosa G, Rodrigues PN, Tomás A, et al. Iron overload favors the elimination of Leishmania infantum from mouse tissues through interaction with reactive oxygen and nitrogen species. PLoS Negl Trop Dis. 2013;7(2):e2061. 